\title{
TO EVALUATE THE PHARMACOTHERAPEUTIC EFFICACY OF TIZANIDINE HYDROCHLORIDE AND GABAPENTIN IN TREATING MYOFASCIAL PAIN-IN A STEPWISE TREATMENT APPROACH
}

\author{
Mohsin Muzaffar Tak1, Altaf Hussain Chalkoo² \\ ${ }^{1}$ Assistant Professor, Department of Oral Medicine and Radiology, Government Dental College, Srinagar. \\ 2 Professor and HOD, Department of Oral Medicine and Radiology, Government Dental College, Srinagar.
}

\begin{abstract}
AIMS: To evaluate, the pharmacotherapeutic efficacy of Tizanidine hydrochloride and Gabapentin in patients with persistent myofascial pain and to identify patient and pain characteristics that may predict treatment outcome.

METHODS: A stepped Pharmacotherapeutic protocol was employed. All 40 patients having persistent facial pain with tenderness of regional muscles were first prescribed Tizanidine hydrochloride. In patients where no response to Tizanidine hydrochloride was observed, Gabapentin was initiated. Outcome was assessed by employing prospective diaries recording pain intensity measured with an 11-point (0-10) Visual Analog scale (VAS). Individual characteristics in these patients and their influence on drug response and outcome were analyzed; specifically, patients treated with Tizanidine hydrochloride were compared with those subsequently treated with Gabapentin. Chisquare and t tests were used to analyze the data.

RESULTS: A total of 22 patients responded to Tizanidine hydrochloride and continued on this regimen, while 18 were resistant to Tizanidine hydrochloride and were subsequently treated with Gabapentin. However when the comparison was done in the intra group pain intensity at the base line and at the end of 6 weeks it was seen that in the group 1 the mean value at the baseline was 6.3 and for group 2 the mean value at the baseline was 5.9 and at the mean value at the end of 6 weeks was 2.11 in group 1 and 2.06 In group 2 which showed a significant improvement in the pain intensity in both the groups, significant statistical difference was noted with the, (P-value<0.05). Patients who did not respond to Tizanidine hydrochloride were characterized by a significantly higher age, more comorbid medical illness, and evidence of more regional pain spread. Overall, a stepped approach employing Tizanidine and gabapentin resulted in overall improvement in the treatment outcome.

CONCLUSION: This study has demonstrated the good pharmacotherapeutic response of persistent myofascial pain, even in more severe cases. Patients who do not respond to Tizanidine may be a distinct subgroup and this needs further investigation. The results also suggest that gabapentin, at a lower dose than previously reported, is a good alternative in Tizanidine hydrochloride resistant patients.
\end{abstract}

KEYWORDS: Tizanidine Hydrochloride, Gabapentin , Myofascial Pain.

HOW TO CITE THIS ARTICLE: Mohsin Muzaffar Tak, Altaf Hussain Chalkoo. "To Evaluate the Pharmacotherapeutic Efficacy of Tizanidine Hydrochloride and Gabapentin in Treating Myofascial Pain-in a Stepwise Treatment Approach". Journal of Evolution of Medical and Dental Sciences 2015; Vol. 4, Issue 89, November 05; Page: 15435-15439, DOI: 10.14260/jemds/2015/2203.

INTRODUCTION: Myofascial pain syndrome (MPS) is characterized by regional pain originating from hyperirritable spots located within taut bands of skeletal muscle, known as myofascial trigger points (MTrPs). ${ }^{1}$

Manual compression of a trigger point produces a local twitch response, with characteristic local and referred pain in a zone of reference. ${ }^{2-6}$ Myofascial pain is caused by recurrent "Biomechanical overloading" and excessive isometric muscle contraction, leading to injured skeletal muscle fibers with increased tone and tension. ${ }^{2-4}$ Repeated mechanical stress leads to muscle injury and fatigue, resulting in the formation of trigger points surrounding skeletal muscle, termed the "injury pool theory".

Myofascial pain syndromes (MPS) that originate from trigger points (TrPs) are among the most frequent pain conditions encountered in the general population.

Financial or Other, Competing Interest: None.

Submission 12-10-2015, Peer Review 13-10-2015,

Acceptance 21-10-2015, Published 04-11-2015.

Corresponding Author:

Dr. Mohsin Muzaffar Tak,

D. No. Habak Zakura Crossing,

Hazratbal, Srinagar-190006, Kashmir.

E-mail: mohsintak@yahoo.com

DOI:10.14260/jemds/2015/2203
However, at the same time, they are most often underdiagnosed or misdiagnosed conditions. ${ }^{7}$ and this circumstance is mainly attributable to incomplete knowledge of their nature, the lack of internationally validated diagnostic criteria and frequent confusion/overlap of symptoms with those of other musculoskeletal pain disorders.

MATERIAL AND METHODS: This study comprised of 40 patients who visited the Department of Oral Medicine \& Radiology over a period of 6 months who were diagnosed for MPS. These patients were interviewed and were subjected to clinical examination.

The data was recorded on the first visit before prescribing the medications. Informed consent was obtained from all participating patients. Patients were asked average pain intensity over the previous week. Pain intensity was rated by employing a VAS Numeric rating scale in which 0 was no pain and 10 the worst imaginable pain. On follow-up, pain diaries were employed so that accurate data on the VAS and treatment were available.

Pain due to trauma event was defined as "posttraumatic" and classified as macro trauma and micro trauma .Patients were also asked a standardized question about whether the pain specifically wakes them from sleep., comorbid chronic medical illnesses, and evidence of more widespread regional pain.

Clinical Examination: The masticatory apparatus (TMJs and masticatory muscles) and neck muscles were examined for sensitivity to palpation. 
The following muscles were examined bilaterally: masseter, temporalis, medial pterygoid, lateral pterygoid, suboccipital group (As one), sternocleidomastoid, and trapezius. Muscle palpation was performed with about 1 to 4 $\mathrm{kg}$ of digital pressure.7,8 Examiners were calibrated on electronic scales to reliably judge this level of digital pressure. Tenderness to palpation was graded on an ordinal scale: 0 (No pain), 1 (Mild), 2 (Moderate), and 3 (Severe), and the individual scores summated to give the total tenderness score (Muscle tenderness score) for each patient.7,8

Inclusion Criteria and Pain Diagnosis: Inclusion criteria comprised a complaint of persistent facial pain, present for a minimum period of 2 months with tenderness in the regional muscles that could reproduce pain. Diagnostic criteria. ${ }^{9}$ Myofascial pain syndromes (MPS) is an established clinical entity, various criteria have been recommended by expert investigators which are variably applied in clinical practice as well as for research purposes.

The criterias defined by Simons et al. in 1999 are most frequently used, according to which an MPS can be diagnosed if five major criteria and at least one out of three minor criteria are satisfied.

The major criteria include (a) localized spontaneous pain; (b) spontaneous pain or altered sensations in the expected referred area for a given $\operatorname{TrP}$ (target area); (c) a taut, palpable band in an accessible muscle; (d) exquisite, localised tenderness in a precise point along the taut band; and (e) a certain degree of reduced range of movement when measurable. Minor criteria include (a) reproduction of spontaneously perceived pain and altered sensations by pressure on the TrP; (b) elicitation of an LTR of muscle fibres by transverse 'snapping' palpation or by needle insertion into the TrP; and (c) pain relieved by muscle stretching or injection of the TrP.

Exclusion Criteria: Cases with referred pain from the TMJ and regional pain syndromes such as neuropathic or neurovascular disorders. Patients were also excluded if they suffered from other pain syndromes (eg, fibromyalgia, migraine), refused pharmacotherapy, or had pain originating from the masticatory muscles that was not treated with medications.

Pharmacotherapeutic Protocol: Patients diagnosed with MFP were started on Tizanidine Hydrocloride 4mg BD daily and their status was reviewed at the end of $2 \mathrm{nd}$ week, the dose was increased to $8 \mathrm{mg}$ BD till the patient reported relief.

At this or any time during treatment, patients with no improvement but intolerable side effects were transferred to Gabapentin 100mg BD daily. For both drugs, the dose was subsequently adjusted according to the patient's response and reported side effects.

Patients with a lack of response at the end of second week or intolerable side effects to either of the Tizanidine drugs were transferred to Gabapentin. Gabapentin treatment was initiated at $100 \mathrm{mg}$ BD daily, and patients were evaluated on weekly basis and the dose was increased gradually to the extent where patient reported pain free or comfortable to a maximum of $900 \mathrm{mg} /$ day by the end of 6 weeks.

Patients experiencing significant improvement during this phase were instructed to stay on the dose that was being prescribed.
At 6 weeks of pharmacotherapy, pain levels were recorded from the pain diaries. Improvement during treatment was judged as simply a lower pain score. Once the study was completed, the level of improvement was calculated using the pain diaries. Significant improvement was defined as $\geq 50 \%$ decrease in baseline pain scores. Patients were not referred to or instructed to perform home care, physiotherapy, or other interventions so as to isolate the effects of pharmacotherapy.

\section{STATISTICTICAL ANALYSES:}

Statistical Methods: SPSS (Version 20.0) and Microsoft Excel software were used to carry out the statistical analysis of data. Data was analysed with the help of descriptive statistics viz., means, standard deviations and percentages. Inter group analysis of data was carried with the help of Student's independent t-test and for intra-group analysis, Paired t-test was employed. Non parametric data was analyzed by Chi-square ttest. P-value less than 0.05 was considered statistically significant.

RESULTS: Since 40 patients met the inclusion criteria and all of them were initially treated with Tizanidine hydrochloride. The mean age of patient was found higher in the Gabapentin group (42.3 years) as compared to the Tizanidine group (32.7 years).

The age of the patients for the Tizanidine group (Group 1) was in the range of 18 years to 46 years and the age of the patients for the Gabapentin group (group 2) was in the range of 28 years to 56 years (P-value $<0.05$ ), (Table-1). Total of 40 patients who met the inclusion criteria comprised of 30 female patients and 10 male patients. (P-value $>0.05$ ) (Table 2 ).

There was not much difference in the tenderness score in the two groups when compared with the mean tenderness score for group 1being 14.3 and for group 2 being 14.1 with a standard deviation of 2.49 and 2.24 respectively as such statistically there was no significant difference (P-value $>0.05$ ) Table 3.

Interincisal mouth opening at base line and after 6 weeks did not show any significant statistical difference when group 1 was compared to group 2 (P-value $>0.05$ ), Table 4 . However when Intra group comparison was done it was observed that there was a significant improvement with the interincisal mouth opening at base line $36.7 \pm 3.28$ to the end of 6 weeks $43.1 \pm 1.96$ in group 1 and interincisal mouth opening at base line $34.9 \pm 3.91$ to the end of 6 weeks $43.3 \pm 2.89$ in group 2, statistical difference in the inter incisal mouth opening at the base line and at the end of 6 weeks, (P-value $<0.05$ ), Table 5 .

Comparison drawn between the two groups to record the pain intensity at the base line and relief in symptoms at the end of 6 weeks did not show any significant statistical difference with the ( $\mathrm{P}$-value $>0.05$ ), Table 6 . However when the comparison was done in the intra group pain intensity at the base line and at the end of 6 weeks it was seen that in the group 1 the mean value at the baseline was 6.3 and for group 2 the mean value at the baseline was 5.9 and the mean value at the end of 6 weeks was 2.11 in group1 and 2.06 In group 2 which showed a significant relief in the pain intensity in both the groups, significant statistical difference was noted with the, (P-value $<0.05)$, Table 7.

Since the patients showed unilateral as well as bilateral pain symptoms, when the inter group comparisons were drawn at the baseline of the treatment and at the end of 6 weeks no significant statistical difference was observed with the (Pvalue $>0.05$ ), Table 7 . 
DISCUSSION: In today's world Myofascial pain has started to emerge as a significant health problem affecting as much as $85 \%$ of the general population sometime in their lifetime while the estimated overall prevalence is $\sim 46 \%{ }^{10}$

The present study was focused on Pharmacotherapeutic and multimodal Pharmacotherapeutic approaches to management of Myofascial pain. The mean baseline pain score of 6.3 in group 1 and 5.9 in group 2 clearly demonstrates the severity of pain in the present patient sample. These pain scores are higher than those in the literature, usually reported as 3 to 5 on a visual analog scale. ${ }^{11,12}$

Treatment of Myofascial pain syndrome is difficult because it may be initiated by peripheral and central mechanisms that appear to be inter-related as Central sensitization would lead to an increased excitability of spinal and supraspinal regions resulting from injury or inflammation-induced activation of peripheral nociceptors. ${ }^{13}$

Tizanidine, an alpha-2 -adrenergic agonist, exerts effects in both the brain and spinal cord, with effects at the second order dorsal horn neurons and wide dynamic range neurons-the same location implicated in the central sensitization process. ${ }^{14}$ Tizanidine decreases spasticity by reinforcing presynaptic inhibition and reinforcing Ia reciprocal and Ib nonreciprocal postsynaptic inhibition. ${ }^{15}$ Tizanidine mechanism of action therefore shows promise for the treatment of myofascial pain, by reducing both pain and associated muscle tone.

Gabapentin and pregabalin have analgesic, anxiolyticlike, and anticonvulsant activity, which reduces the release of several neurochemicals, including glutamate, noradrenaline, and substance P.16 MPS may be mediated at the spinal level; therefore, anticonvulsants might be considered in its treatment. ${ }^{17}$ To date, there are no RCTs of anticonvulsants in the treatment of MPS. A Cochrane literature review found that very few trials examined anticonvulsant effectiveness on acute pain; most examined their use in chronic pain. ${ }^{18}$

Gabapentin has been reported to be superior to placebo in reducing reported pain, masticatory muscle hyperalgesia, and the impact of MFP on daily functioning; reduction in muscle tenderness was observed after 8 weeks and the effects on pain appeared only after 12 weeks of therapy at a mean dose of gabapentin of about $3,400 \mathrm{mg}$ daily. ${ }^{19}$

The pharmacologic mode of action of Gabapentin is well suited to situations in which central sensitization is suspected. Gabapentin is thought to act primarily via blockade of L-type calcium channels, which modulate neurotransmitter release, and thus inhibits glutamate release in the spinal cord.20

Gabapentin is therefore a good choice when central sensitization may be present. ${ }^{21-23}$ Since there is evidence of prominent central sensitization in MFP patients, ${ }^{19,21}$ gabapentin may be a good option for them, and patients with more regional spread of pain and medical comorbidities also may respond well to gabapentin.

The significant differences between the group treated with Tizanidine and the patients who did not respond to Tizanidine and subsequently treated with Gabapentin were increased age, more comorbid chronic medical illnesses, and evidence of more widespread regional pain.
Comorbid medical illness is age-dependent, and one of these may therefore have been a related confounding factor. Alternatively, taking all three factors together, the group taking gabapentin may have signified patients at a different disease stage. Comorbid illness is common in patients with MFP and particularly in more severe cases. ${ }^{24}$ The more widespread regional pain may indicate more prominent central sensitization.

A vast range of other pharmacotherupetic agents have been used in the management of Myofascial pain. In certain studies Amitriptyline was shown to be somewhat effective in reducing pain, without changing the patient's pain or pressure threshold. ${ }^{25}$

Injectable diclofenac was also shown to provide significantly better pain relief, as measured on the VAS, than injections of lidocaine in the treatment of MPS. ${ }^{26}$ Significant risks associated with prolonged use of NSAIDS, including gastrointestinal bleeding and renal toxicity, make diclofenac a less favorable treatment strategy for patients who may require chronic treatment. ${ }^{27,28}$ Capsaicin decreased chronic neck pain, as measured on a VAS, but no significant improvement in affective pain levels, as measured by the McGill pain questionnaire, was shown. ${ }^{29}$

In light of the variable results with other pharmacologic agents and our study results, tizanidine has a role as a first-line medication in the treatment of MPS. No serious adverse events occurred in this study. The most common adverse events with tizanidine are dry mouth, somnolence/sedation, asthenia, and dizziness. ${ }^{30}$ When compared to other studies the rates of dry mouth and dizziness in this study, and other adverse effects as reported in some of the studies in the past were less because of the lower dose of Tizanidine hydrochloride and Gabapentin used in the present study.

CONCLUSION: Tizanidine is effective in the treatment of subacute and chronic myofascial pain syndrome. Pain, disability, and muscle tenderness were significantly reduced. No serious adverse events occurred in this study. Tizanidine should be considered as a first-line pharmacologic agent for the treatment of myofascial pain. Gabapentin is therefore a good choice when central sensitization may be present. Increased age, more comorbid chronic medical illnesses, and evidence of more widespread regional pain also favour the use of Gabapentin. However studies should be conducted with a larger sample size with different age groups and with populations belonging to different geographical strata so as to further establish the use of these Pharmacotherapeutic agents.

\section{REFERENCES:}

1. Leite F, Atallah A, El Dib R, et al. Cyclobenzaprine for the treatment of myofascial pain in adults. Cochrane Database Syst Rev. 2009;3: CD006830. [PubMed].

2. Alvarez DJ, Rockwell PG Trigger points: diagnosis and management. Am Fam Physician2002; 65: 653-660.

3. Borg-Stein J, Simons DG .Focused review: myofascial pain. Arch PhysMed Rehabil 2002; 83:S40-47,S48-9.

4. Simons DG, Travell J Myofascial Pain and Dysfunction: The Trigger PointManual. Lippincott Williams \& Williams.

5. Han SC, Harrison P .Myofascial pain syndrome and triggerpoint management. Reg Anesth1997; 22: 89-101. 
6. Cummings TM, White AR.Needling therapies in the management of myofascial trigger point pain: a systematic review. Arch Phys Med Rehabil2001; 82:986992.

7. Benoliel R, Eliav E, Sharav Y. Classification of chronic Orofacial pain: Applicability of chronic headache criteria. Oral Surg OralMed Oral Pathol Oral Radiol Endod 2010; 110:729-737.

8. Benoliel R, Eliav E, Sharav Y. Self-reports of pain-related awakenings in persistent orofacial pain patients. J Orofac Pain 2009; 23:330-338.

9. Simons DG, Travell JG, Simons LS. Upper half of body. In: Travell \& Simons' myofascial pain and dysfunction. The trigger point manual. 2nd ed., vol. 1. Baltimore: Williams \& Wilkins; 1999. 1038.

10. D. G. Simons, "Clinical and etiological update of myofascial pain from trigger points," Journal of Musculoskeletal Pain, vol. 4, no. 1-2, pp. 93-121, 1996.

11. Kino K, Sugisaki M, Haketa $\mathrm{T}$, et al. The comparison between pains, difficulties in function, and associating factors of patients in subtypes of temporomandibular disorders. J Oral Rehabil 2005; 32:315-325.

12. van Grootel RJ, van der Glas HW, Buchner R, de Leeuw JR, Passchier J. Patterns of pain variation related to myogenous temporomandibular disorders. Clin J Pain 2005;21:154-165.

13. Bennett RM. Emerging concepts in the neurobiology of chronic pain: Evidence of abnormal sensory processing in fibromyalgia. Mayo Clin Proc 1999; 74:385- 398.

14. Davies J, Johnston SE, Hill DR et al. Tizanidine (DS 103282), a centrally acting muscle relaxant, selectively depresses excitation of feline dorsal horn neurons to noxious stimuli by an action at alpha 2 adrenoreceptors. Neurosci Lett 1984; 48:197-202.

15. Yanagisawa N, Tanaka R, Ito Z. Reciprocal Ia inhibition in spastic hemiplegia of man. Brain 1976; 99:555-574.

16. Crofford L, Rowbotham M, Mease P, et al. Pregabalin for the treatment of fibromyalgiasyndrome.ArthritisRheum. 2005;52:1264-1273.

17. Wheeler A. Myofascial pain disorders: theory to therapy. Drugs. 2004;64:45-62.
18. Wiffen P, Collins S, McQuay H, Carrol D, Jadad A, Moore A. Anticonvulsant drugs for acute and chronic pain. Cochrane Database Syst Rev. 2005;20(3):CD001133.

19. Kimos P, Biggs C, Mah J, et al. Analgesic action of Gabapentin on chronic pain in the masticatory muscles: A randomized controlled trial. Pain 2007;127:151-160.

20. Coderre TJ, Kumar N, Lefebvre CD, Yu JS. Evidence that Gabapentin reduces neuropathic pain by inhibiting the spinal release of glutamate. J Neurochem 2005;94:11311139.

21. Gottrup H, Juhl G, Kristensen AD, et al. Chronic oral Gabapentin reduces elements of central sensitization in human experimental hyperalgesia. Anesthesiology 2004;101:1400-1408.

22. Nicholson B. Gabapentin use in neuropathic pain syndromes. Acta Neurol Scand 2000;101:359-371.

23. Tuchman M, Barrett JA, Donevan S, Hedberg TG, Taylor CP. Central sensitization and $\mathrm{Ca}(\mathrm{V})$ alpha(2)delta ligands in chronic pain syndromes: Pathologic processes and pharmacologic effect. J Pain 2010;11:1241-1249.

24. Aaron LA, Burke MM, Buchwald D. Overlapping conditions among patients with chronic fatigue syndrome, fibromyalgia, and temporomandibular disorder. Arch Intern Med 2000;160:221-227.

25. Bendtsen L, Jensen R.Amitriptyline reduces myofascial tenderness in patients with chronic tension-type headache. Cephalagia 2000; 20:603-610.

26. Frost A. Diclofenac versus lidocaine as injection therapy in myofascial pain. Scand J Rheumatol 1986; 15:153-156.

27. Griffin MR. Epidemiology of nonsteroidal antiinflammatory drug-associated gastrointestinal injury. Am J Med 1998; 104:23-29.

28. Whelton A. Nephrotoxicity of nonsteroidal antiinflammatory drugs: physiologic foundations and clinical implications. Am J Med 1999; 106:13-24.

29. Mathias BJ, Dillingham TR, Zeigler DN et al. Topical capsaicin for chronic neck pain; a pilot study. Am J Phys Med Rehabil 1995; 71:39-44.

30. Zanaflex Package Insert. Physicians Desk Reference 2001. Montvale, NJ, Medical Economics Company, Inc., New Jersey, 2001, pp 670-672.

Group 1: Tizanidine Group

Group 2: Gabapentin Group

\begin{tabular}{|c|c|c|c|c|}
\hline Age (years) & Mean & SD & Range & \multirow{2}{*}{ P-value } \\
\hline Group 1 & 32.7 & 8.04 & $18-46$ & \multirow{2}{*}{$0.0007^{*}$} \\
\hline Group 2 Table 1: Age distribution of Study patients \\
\hline
\end{tabular}

*Statistically Significant Difference (P-value<0.05)

\begin{tabular}{|c|c|c|c|c|c|}
\hline \multirow{2}{*}{ Gender } & \multicolumn{2}{|c|}{ Group 1 } & \multicolumn{2}{c|}{ Group 2 } & \multirow{2}{*}{ P-value } \\
\cline { 2 - 5 } & No. & \%age & No. & \%age & \multirow{2}{*}{$0.714 \#$} \\
\hline Male & 6 & 27.3 & 4 & 22.2 & \multirow{2}{*}{} \\
\hline Female & 16 & 72.7 & 14 & 77.8 & \\
\hline Total & $\mathbf{2 2}$ & $\mathbf{1 0 0}$ & $\mathbf{1 8}$ & $\mathbf{1 0 0}$ & \\
\hline \multicolumn{6}{|c|}{ Table 2: Gender distribution of study patients } \\
\hline
\end{tabular}

\#Statistically Non-significant Difference (P-value >0.05) 


\begin{tabular}{|c|c|c|c|c|}
\hline Tenderness & Mean & SD & Range & P-value \\
\hline Group 1 & 14.3 & 2.49 & $11-19$ & \multirow{2}{*}{$0.731^{\#}$} \\
\hline Group 2 & 14.1 & 2.24 & $9-19$ & \\
\hline \multicolumn{7}{|c|}{ Table 3: Comparison based on tenderness in two groups } \\
\hline
\end{tabular}

\#Statistically Non-significant Difference (P-value>0.05)

\begin{tabular}{|c|c|c|c|c|c|}
\hline \multirow{2}{*}{$\begin{array}{c}\text { Interincisal } \\
\text { Mouth Opening }\end{array}$} & \multicolumn{2}{|c|}{$\begin{array}{c}\text { Group 1 } \\
\text { (n=22) }\end{array}$} & \multicolumn{2}{c|}{$\begin{array}{c}\text { Group 2 } \\
\text { (n=18) }\end{array}$} & \multirow{2}{*}{ P-value } \\
\cline { 2 - 5 } & Mean & SD & Mean & SD & \\
\hline Baseline & 36.7 & 3.28 & 34.9 & 3.91 & $0.114^{\#}$ \\
\hline 6 Weeks & 43.1 & 1.96 & 43.3 & 2.89 & $0.799^{\#}$ \\
\hline \multicolumn{3}{|c|}{ Table 4: Comparison based on Interincisal mouth opening } \\
between two groups at baseline and 6 weeks \\
\hline
\end{tabular}

\#Statistically Non-significant Difference (P-value>0.05)

\begin{tabular}{|c|c|c|c|c|c|c|}
\hline $\begin{array}{c}\text { Interincisal } \\
\text { Mouth Opening }\end{array}$ & \multicolumn{3}{|c|}{ Group 1 (n=22) } & \multicolumn{3}{c|}{ Group 2 (n=18) } \\
\cline { 2 - 7 } & Mean \pm SD & $\begin{array}{c}\text { Diff. } \\
\text { From BL }\end{array}$ & P-value & Mean \pm SD & $\begin{array}{c}\text { Diff. } \\
\text { From BL }\end{array}$ & P-value \\
\hline Baseline & $36.7 \pm 3.28$ & - & - & $34.9 \pm 3.91$ & - & - \\
\hline 6 Weeks & $43.1 \pm 1.96$ & -6.4 & $<0.001^{*}$ & $43.3 \pm 2.89$ & -8.4 & $<0.001^{*}$ \\
\hline \multicolumn{6}{r}{ Table 5: Intra-group comparison of interincisal mouth opening } \\
\hline
\end{tabular}

*Statistically Significant Difference From Baseline (P-value<0.05)

\begin{tabular}{|c|c|c|c|c|c|}
\hline \multirow{2}{*}{ VAS Score } & \multicolumn{2}{|c|}{ Group 1 (n=22) } & \multicolumn{2}{c|}{ Group 2 (n=18) } & \multirow{2}{*}{ P-value } \\
\cline { 2 - 5 } & Mean & SD & Mean & SD & \\
\hline Baseline & 6.3 & 0.78 & 5.9 & 0.67 & $0.076^{\#}$ \\
\hline 6 Weeks & 2.11 & 0.76 & 2.06 & 0.42 & $0.772^{\#}$ \\
\hline \multicolumn{7}{|c}{ Table 6: Comparison based on(Pain intensity) } \\
\hline
\end{tabular}

\#Statistically Non-significant Difference (P-value>0.05)

\begin{tabular}{|c|c|c|c|c|c|c|}
\hline \multirow{2}{*}{ VAS Score } & \multicolumn{3}{|c|}{ Group 1 (n=22) } & \multicolumn{3}{c|}{ Group 2 (n=18) } \\
\cline { 2 - 7 } & Mean \pm SD & Diff. From BL & P-value & Mean \pm SD & Diff. From BL & P-value \\
\hline Baseline & $6.3 \pm 0.78$ & - & - & $5.9 \pm 0.67$ & - & - \\
\hline 6 Weeks & $2.11 \pm 0.76$ & 4.19 & $<0.001^{*}$ & $2.06 \pm 0.42$ & 3.84 & $<0.001^{*}$ \\
\hline \multicolumn{3}{|c|}{ Table 7: Intra-group comparison of VAS score } \\
\hline
\end{tabular}

*Statistically Significant Difference From Baseline (P-value<0.05)

\begin{tabular}{|c|c|c|c|c|c|}
\hline \multirow{2}{*}{ Pain Symptoms } & \multicolumn{2}{|c|}{ Group 1 } & \multicolumn{2}{c|}{ Group 2 } & \multirow{2}{*}{ P-value } \\
\cline { 2 - 5 } & No. & \%age & No. & \%age & \multirow{2}{*}{$0.714^{\#}$} \\
\hline Unilateral & 6 & 27.3 & 4 & 22.2 & \\
\hline Bilateral & 16 & 72.7 & 14 & 77.8 & \\
\hline Total & $\mathbf{2 2}$ & $\mathbf{1 0 0}$ & $\mathbf{1 8}$ & $\mathbf{1 0 0}$ & \\
\hline \multicolumn{6}{|c|}{$\begin{array}{c}\text { Table 8: Showing unilateral/bilateral } \\
\text { pain symptoms in study patients }\end{array}$} \\
\hline
\end{tabular}

\#Statistically Non-significant Difference (P-value>0.05) 